\title{
Evaluation Study of Internet Commercial Sustainable Development under the New Commercial Civilization
}

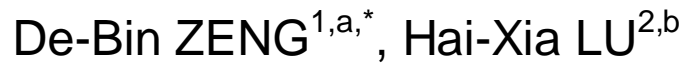 \\ ${ }^{1}$ Department of Business, Jincheng College of Sichuan University \\ ${ }^{2}$ College of tourism and urban planning of Chengdu University of Technology Sichuan Chengdu, \\ 610059, Sichuan, 610041 \\ a163bin@163.com, bluhaixia@cdut.cn
}

Keywords: new business paradigm, e-businessman, sustainable development, index system, Data Envelopment Analysis

\begin{abstract}
. the new business paradigm in the information era takes openness, transparence, sharing and responsibility as a fundamental principle. Acting as the subject of the new business paradigm, the issues concerned about sustainable development of e-businessman has become the hotspot of attention by academia. Based on a deeply understanding of the new business paradigm contents, this thesis formed an elementary evaluation index system on the sustainable development of e-businessman, and through the means of factor analysis and PCA of SPSS software, the key indicators fixed then, furtherly it transforms the key indicators into input-output indicator which could be evaluated by DEA model, then it takes Data Envelopment Analysis to establish a DEA model of the e-businessman' input-output sustainable effectiveness evaluation. Finally it took an empirical analyses on an e-businessman.
\end{abstract}

\section{Introduction}

The new commercial civilization, information age is the commercial civilization, refers to the productivity and relations of production informatization informatization and Internet mode of production is the symbol of the commercial civilization, "open, sharing, responsibility, globalization" is the important connotation of the new commercial civilization, [1] network is the subject of new commercial civilization, refers to the continuous engaged in business activities using the electronic commerce mode of personal and business, which includes the person in charge of the enterprise, personal, business, individual operators and business operator. As of the first half of 2011, the number of China network has expanded to 83000000. Network development over the past ten years, is to give birth, development, expand, mainstream ten years, network to develop the new ten years, will be the net change society, new commercial society gradually grow in ten years, the ${ }^{[2]}$ network development environment gradually from the traditional to the network system to "open, transparent, share, responsibility" as the basic characteristics of the new commercial civilization, in this context, the network how to maintain strong momentum of development, sustainable management of the shop is very important. The network development has encountered a bottleneck, some business development remain stagnant, online transaction size reaches a certain amount, it is difficult to break through the bigger and stronger, some merchants and abandon. So the research is of great practical significance to the sustainable development network new business civilization era.

\section{Research Status:}

At present, the new commercial civilization the main outcome of the study is China Academy of Social Sciences Research Center of informatization and Ali research center in 2010 April release of 
"new business civilization Research Report", pointed out that the new commercial civilization connotation, characteristics, structure, at the same time, Alibaba group research center also issued a "Declaration", the new commercial civilization "new business civilization study guide" and a series of research results. Study of [1] experts and scholars on the new commercial civilization includes the following aspects: (1) the new commercial civilization, development path. Lei Xiaoyu put forward the crisis at home and abroad and the outbreak, one disaster after another, ecbolic new business civilization [3]. Guan Yixin looking for new business civilization start [4] (2)from the Analects of confucius. The new commercial civilization and the electronic commerce environment. If the whole $\mathrm{Li}, \mathrm{Lu}$ Jing, from different angles on the changes of ecosystem of electronic commerce under the new commercial civilization. [5] [6]

In the aspect of network research results, mainly reflected net research report published from 2004 in the Alibaba group research center, pointed out that the network groups after "emerge (2004)", "existence and base (2005-2006)", "into the rise (2007)", "ecological (2008)", "Socialization i(2009)", "personalized fission(2010) "Across the critical point (2011)", "small is beautiful (2012)". [2]." the six stages of development. [2] and many experts and scholars have published about network copyright. The current research on network is mainly following the rise, development and influence of network. Liang Chunxiao, such as analysis of the rise of high throughout the development and influence of network. Analysis of [7] of network development stage. Hu Guilan believes that the network has experienced 4 stages inoculation, survival, and based on the emerging growth and expand operations, each stage has different characteristics [8]. Study the network depth. Such as the Qing Jing developed business competency model, and use the model to promote the Chinese network market construction [9] .

In summary we can see, the connotation, the research on the development of new network commercial civilization under the concentrated in the new commercial civilization form, development path, the network of research is developing and changing trends of network. For the sustainable development of the network of business and other aspects of research. This thesis attempts to research in the new commercial civilization network how to continue the business shop, from the microscopic to break through the bottleneck, bigger and stronger.

\section{The Preliminary Construction of Evaluation Index System of Sustainable Development Network}

Preliminary evaluation index system of sustainable development of business is business success factors in the original on the basis of evaluation index system (the previous research results the author), closely around the factors affecting the sustainable management of the network, network quality, network environment, strategic planning, product, shop five aspects to construct a preliminary evaluation index system the formation, 5 first level indicators, 25 level two indexes. As specified in Table 1. 
Table 1. All levels of target network evaluation index system of sustainable development under the new commercial civilization

\begin{tabular}{|c|c|c|}
\hline \multirow{26}{*}{$\begin{array}{l}\text { The evaluation } \\
\text { index system of } \\
\text { the sustainable } \\
\text { development } \\
\text { network A }\end{array}$} & First class index & Second class index \\
\hline & \multirow{8}{*}{ Commercial quality } & credibility and integrity $C_{11}$ \\
\hline & & diligenrC $_{12}$ \\
\hline & & willpowerC $_{13}$ \\
\hline & & learning ability $\mathrm{C}_{14}$ \\
\hline & & communication skills $C_{15}$ \\
\hline & & $\begin{array}{l}\text { the market sensitive observation } \\
\text { abilityC } \mathrm{C}_{16}\end{array}$ \\
\hline & & Knowledge and skills reserves $\mathrm{C}_{17}$ \\
\hline & & Organization and management ability $\mathrm{C}_{18}$ \\
\hline & \multirow{3}{*}{$\begin{array}{l}\text { Influence of the macro } \\
\text { environment } \mathrm{B}_{2}\end{array}$} & $\begin{array}{l}\text { The government's attitude on the } \\
\text { network } C_{21}\end{array}$ \\
\hline & & $\begin{array}{l}\text { Consumer attitude toward online } \\
\text { shopping } \mathrm{C}_{22}\end{array}$ \\
\hline & & $\begin{array}{l}\text { The development of network technology } \\
\text { supportC } 23\end{array}$ \\
\hline & \multirow{3}{*}{$\begin{array}{l}\text { Strategic target planning } \\
\text { network } \mathrm{B}_{3}\end{array}$} & $\begin{array}{l}\text { The network of strategic development } \\
\text { consciousness } C_{31}\end{array}$ \\
\hline & & The network of brand awarenessC $\mathrm{C}_{32}$ \\
\hline & & The network of team consciousness $\mathrm{C}_{33}$ \\
\hline & \multirow{7}{*}{ Products $\mathrm{B}_{4}$} & The price of the products $\mathrm{C}_{41}$ \\
\hline & & The quality of the products $\mathrm{C}_{42}$ \\
\hline & & Product priceC 43 \\
\hline & & The technological content of products $\mathrm{C}_{44}$ \\
\hline & & Green products $\mathrm{C}_{45}$ \\
\hline & & A product's popularity $\mathrm{C}_{46}$ \\
\hline & & Product development potentialC 47 \\
\hline & \multirow{4}{*}{ The shop $\mathrm{B}_{5}$} & The size of the shopC $C_{51}$ \\
\hline & & Shop in the life cycleC $\mathrm{C}_{52}$ \\
\hline & & The shop has a customer recognition $\mathrm{C}_{53}$ \\
\hline & & The shop has a customer loyalty $\mathrm{C}_{54}$ \\
\hline
\end{tabular}

\section{Determination of Business Sustainable Development. The Final Indicators}

In the establishment of sustainable development evaluation index system to give preliminary, questionnaire design, distribution, collection, analysis, principal component analysis and factor analysis using SPSS software, the optimization index system.

\section{The Principal Components and Factor Analysis of Data Obtained in [13]}

(1) The KMO statistics and the Bartlett test on the sample data using SPSS software KMO=0.772 from the Table 2, approximate Bartlett test, the chi square value is 654.785 , the corresponding 
probability value $\mathrm{p}=0.000<0.01$, which allows the use of factor analysis.

Table 2 business sustainable development evaluation index of KMO value and Bartlett test

\begin{tabular}{|c|c|c|}
\hline & \multirow{2}{*}{$\begin{array}{r}.772 \\
654.785\end{array}$} \\
\hline \multirow{3}{*}{ The sphericity test Bartlett } & The sphericity test Bartlett Approximate chi square & \\
\hline & df & 210 \\
\hline & & .000 \\
\hline
\end{tabular}

(2) Extract the evaluation index of public factor

Through principal component analysis, get the common factor variance table. The initial value of 1 , can be seen when the original evaluation index variables using principal component analysis method to extract factors, all of the variance of the original variables can be explained, but all the variable information loss is close to $30 \%$, there are many factors and alternative. But the number of the number of extraction of evaluation index of public factor than the original variables, so take a common factor variance method to extract the factor effect is not very ideal, therefore, combined with the original variable factor explain the total variance and principal component analysis of gravel map provides factor.

At the same time, according to the factors that explain the total variance of the original variables table.We can see from the output of the cumulative contribution of six factors, the characteristics of the extracted values of the rate of $60.902 \%$, so it can be combined with the 6 evaluation factors summarized evaluation business sustainable development comprehensive evaluation.

According to the characteristic value of the scree plot, corresponding to the second factor is the first turning point line, corresponding to the seventh factor is the second turning point.

Based on the above analysis, 6 common factors ultimately determine

According to table the factor load matrix after rotation, the key evaluation index can be summarized network shop, business quality, product, planning. See Fig.1. 


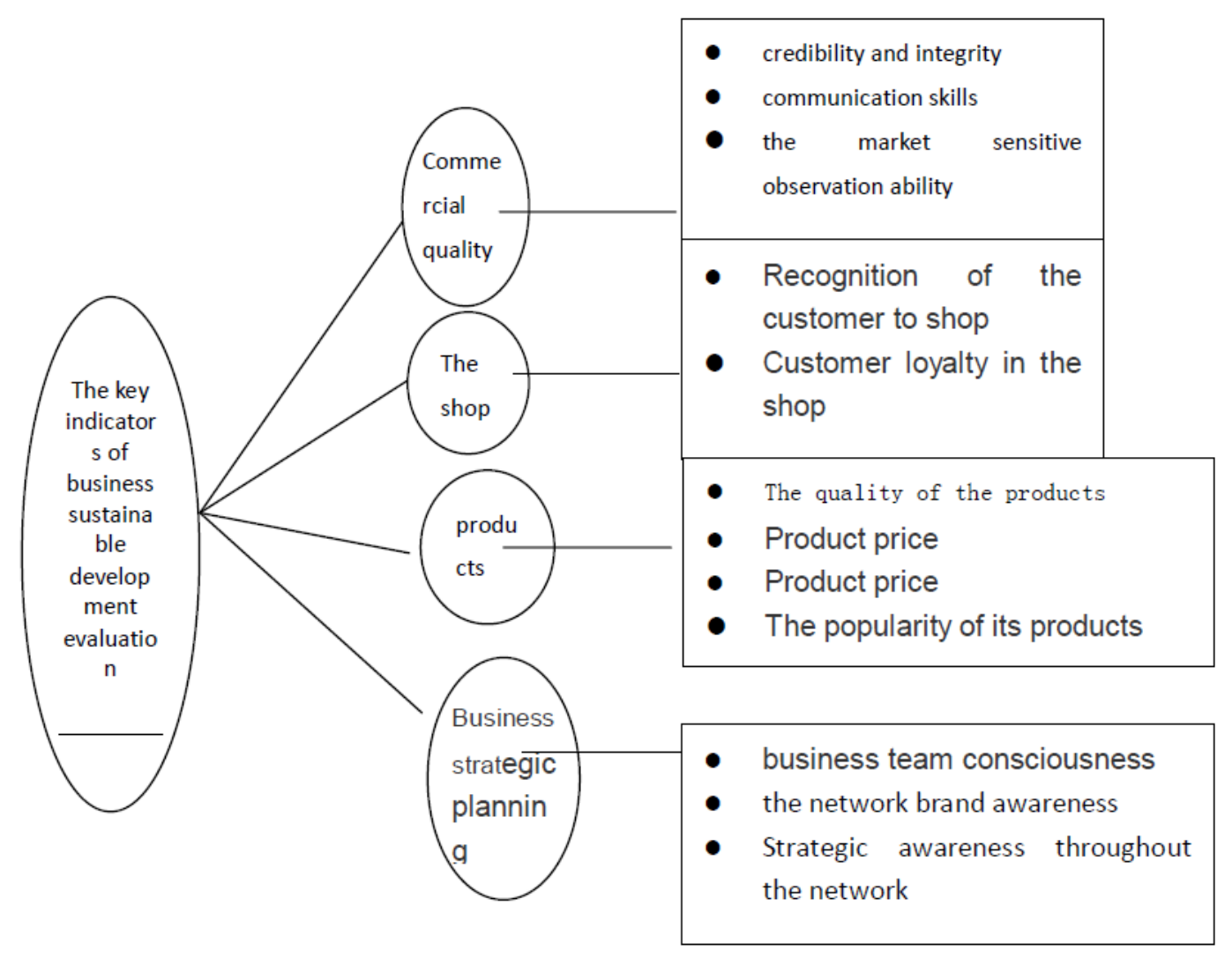

Fig. 2 Business sustainable development key indicator diagram

\section{The Establishment of DEA Model to Evaluate the Sustainable Development of the Network}

Evaluation of business sustainable development can use data envelopment analysis method, analytic network process, because the network of sustainable development is a dynamic and continuous process, with time sequence, so the data envelopment analysis (DEA) input and output in thought, key indicators will be determined in advance into more easily measure the input and output indicators of sustainable development at the same time, net research output results.

[15] established the DEA model the continuous effectiveness of 4.1 network

Select the DEA model used to study the continued effectiveness of the network input and output.

(1) model

$\mathrm{N}$ factor for the sustainable development of the hypothesis network (called the decision making unit, decision making units, referred to as DMU), the $\mathrm{N}$ decision making units are comparable, each decision unit has $m$ types of input and output of s types, $n$ decision unit, its network of business investment output model as shown in Fig.3:

Decision making unit recorded as in figure, $1 \leq \mathrm{J} \leq \mathrm{n}$,

$=$ the No. I input input, $\geq 0$,

$=$ output to the $\mathrm{R}$ output, $\geq 0$,

The $\mathrm{I}$ is a measure of input, is a measure of the $\mathrm{R}$ output of the $\mathrm{i}=1,2, \ldots \mathrm{R}=1,2, \mathrm{~m}, \ldots, \mathrm{s}$, 


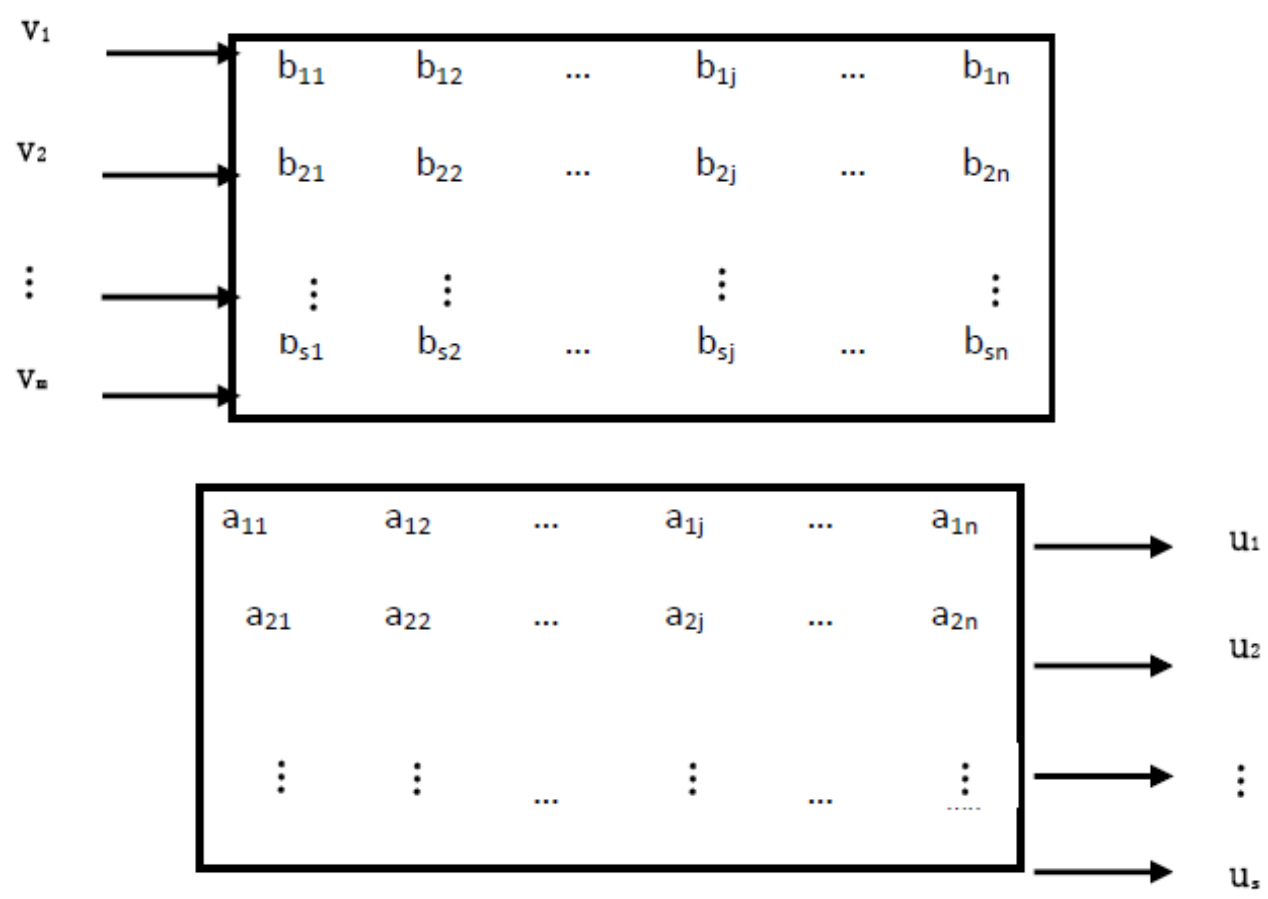

Input output model Fig 2 business sustainable development evaluation of decision making units Among them, respectively for the input and output vector, vector $\mathrm{u}$ and $\mathrm{V}$ respectively for $\mathrm{M}$ input and $\mathrm{s}$ output corresponding to $\mathrm{u}$ and $\mathrm{V}$, the weight coefficient, efficiency evaluation index decision making unit $\mathrm{J}:=$, efficiency index meaning is: the investment under the weight coefficient, $\mathrm{u}$ and $\mathrm{V}$, and output when the ratio of input and output for.

The introduction of non Archimedes concept of infinitesimal, let $\xi$ is non Archimedes infinitely small quantity (non-Archimedan), it is a less than any positive number is a number greater than zero, then the establishment of business sustainable development evaluation programming model as shown in equation 4-1:

$$
\left\{\begin{array}{c}
\min \left[\theta-\xi\left(^{e^{\mathrm{T}} \mathrm{S}^{-}}+\mathrm{e}^{\mathrm{T}} \mathrm{S}^{+}\right)\right] \\
\sum_{\mathrm{j}=1}^{\mathrm{n}} \mathrm{A}_{\mathrm{j} \lambda_{\mathrm{j}}}+\mathrm{S}^{-}=\theta \mathrm{A}_{0,} \\
\sum_{\mathrm{j}=1}^{\mathrm{n}} \mathrm{B}_{\mathrm{j} \lambda_{\mathrm{j}}}-\mathrm{S}^{+}=\mathrm{B}_{0,}, \\
\lambda_{\mathrm{j}} \geq 0, \mathrm{j}=1,2, \ldots \mathrm{n} \\
\mathrm{S}^{+} \geq 0, \mathrm{~S}^{-} \geq 0
\end{array}\right.
$$

\section{Build Output Index Into the Sustainable Development of the Network}

According to the key evaluation index system of the sustainable development network in front of, will be the most important evaluation index into easy to quantify index bu siness model evaluation, which is based on the research on the sustainable and effective input output.

The evaluation index of business sustainable development four important indicators: the network quality, shop, product, planning into an index input output analysis method.

(1) will be the most important network quality indexes into the network of personal investment index re learning and team training,

(2) will be the most important in the shop to shop customer acceptance and loyalty into the shop management fees and the rate of return on net assets,

(3) the most important product in the quality, price, price and popularity into product input costs and sales revenue,

(4) the consciousness of team, brand strategy planning, the most important in the network into the input index team training fee and the net rate of return on total assets.

After transformation, the network of sustainable development into measuring indicators are: 
network to individual learning, team training, network products into the fee, shop management fees. Business sustainable development indicators: output network product sales income, net rate of return on net assets, net rate of return on total assets. See Fig. 4:

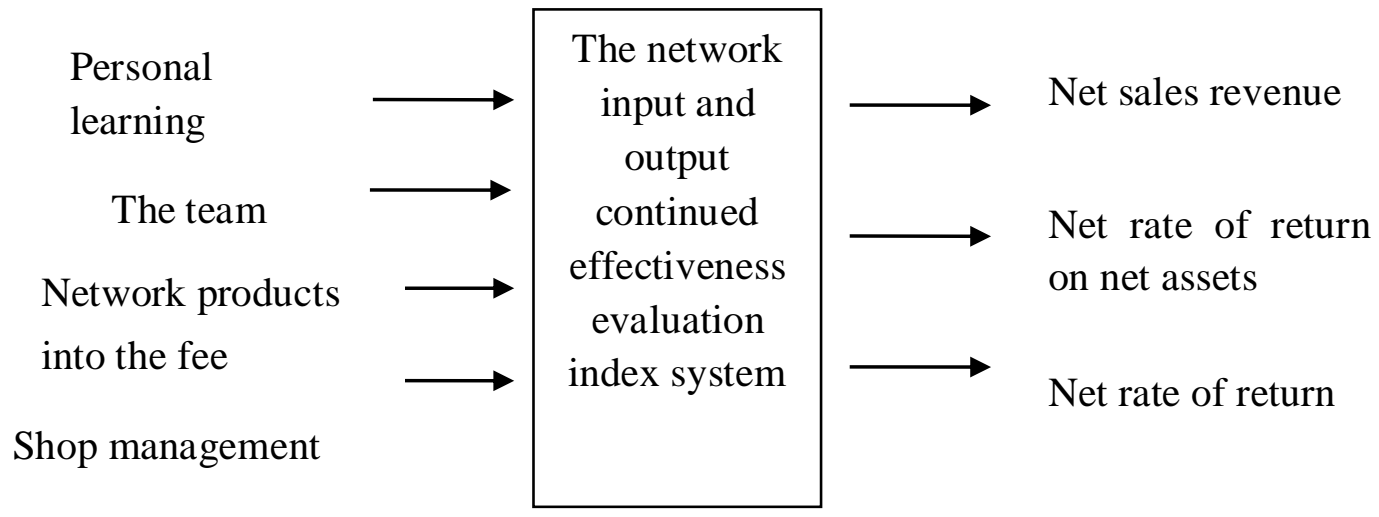

Fig.3 The network input and output continued effectiveness evaluation index system

\section{Conclusion}

The new commercial civilization emerged, the network in the massive personalized consumer demand, intense market competition, technological progress change rapidly and complex macroscopic environment, how to continue to operate each network business concern. In this foundation has been research, in-depth understanding of the connotation of the new commercial civilization, put forward a preliminary evaluation index system of sustainable development of the network, including network quality, network environment, strategic planning, product, shop 5 first level indicators, 25 level two indexes. Using factor analysis and principal components analysis, determine the key index system of sustainable development of the network, including network planning, product quality, shop, business strategy 4 first level indexes and 12 two level indexes. Because the network for sustainable development is a dynamic and continuous process, with time sequence, so the key evaluation index system into input and output indicators to measure, and constructs the evaluation network data envelopment analysis (DEA) model of sustainable development. To provide reference for the sustainable management of network.

\section{Reference}

[1] Alibaba group research center.2010 New Business Civilization Research Report [EB/OL]. 2010.11.6

$\mathrm{Http} / / / \mathrm{www}$. aliresearch.com/brief/downbrief/11120/

[2] Alibaba group research center. 2010 -2012study network to develop the annual [EB/OL]. 2010.8, Http://www.aliresearch.com/index.php? M-cms-q-view-id-67085.html

[3] Lei Xiaoyu. Pains the birth of a new commercial civilization China entrepreneur [J]..2008 (24): $74-75$

[4] tube Yi Xin. The starting point of a new commercial civilization where "the Analects of Confucius" -- Interpretation of [J]. enterprise civilization.2010 (2): 35-36

[5] whole li. To restore order in the new commercial civilization under the electronic commerce electronic commerce [J]..2009 (1): 61-61

[6] Lu Jing, the bear. Chen Ping to open a new scene Alibaba commercial civilization [J]. transport manager in the world,.2010 (5): 28-30

[7] Liang Chunxiao, Song Fei. Net to win the world: the new perspective of Alibaba commercial 
[M]. Beijing: CITIC publishing house.2008

[8] [J]..2009 network environment. The rise of glory (8): 24-25

[9] $\mathrm{Hu}$ Guilan, Zhu Yongyue. The network economy "network business" entrepreneurship development stage [J]. Journal of Jiangsu University (SOCIAL SCIENCE EDITION).2010 (1): $24-25$

[10] Ching Ching. The network construction of competency model and assessment of the [D]. Wuhan: Wuhan University of Technology doctoral dissertation.2010

[11] Du Zhimin, Guo Yibin. Investigation and application of SPSS. Publishing House of electronics industry.2010:5

[12] Ma Zhan shin. Data envelopment analysis model and method of [M]. science and Technology Press.2010:4 